NASA Technical Memorandum 105256

45759

AIAA-91-3553

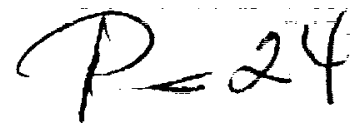

\title{
The NASA Cryogenic Fluid Management Technology Program Plan
}

(NASA-TH-105250) THE NASA CRYOGENIC FLUIO MANAGEMENT TECHNOLOGY PROGRAM PLAN (NASA)

240 CSCL $21 \mathrm{H}$

N91-3?161

Uncl is

$63 / 20 \quad 0045759$

James R. Faddoul

Lewis Research Center

Cleveland, Ohio

and

Stanley D. McIntyre

- Marshall Space Flight Center

Huntsville, Alabama

Prepared for the

Conference on Advanced Space Exploration Initiative Technologies cosponsored by AIAA, NASA, and OAI

Cleveland, Ohio, September 4-6, 1991 


\section{The nasa Cryogenic fluid Management Technology Program Plan}

\author{
JaMES R. FADDOUL \\ Lewis Research Center \\ Cleveland, OH
}

Stanley D. MCInTYRe

Marshall Space flight Center

HUNTSVILLE, AL

\section{ABSTRACT}

During the past three decades, NASA has been designing and using large quantities of cryogenic fluids for propulsion system propellants, coolants for experiments, and for environmental control systems. As a consequence, an erroneous conclusion has been drawn that the technology exists for using large quantities of cryogens in space for long periods of time. This paper attempts to dispel that myth and to present the technology needs that require development in order to support the NASA programs of the future. A NASA program, developed through the impetus of MSFC and LeRC personnel and supported by all NASA centers is outlined. The current state-of-the-art is discussed along with specific needs for near future missions. Then, using the space Exploration Initiative mission set, cost/benefit projections are made for development of advanced cryogenic fluid management techniques. Earth based and space based test programs are discussed relative to the technology requirements for liquid storage, supply, and transfer and for fluid transfer and advanced instrumentation.

\section{INTRODUCTION}

For more than 30 years, NASA has been pursuing propulsion systems and manned activities which have required the use of cryogenic liquids. The most common are liquid oxygen, nitrogen, hydrogen and helium. Huge quantities (tons) of oxygen and hydrogen have been used on saturn vehicles for transporting astronauts to the moon. And, even larger quantities are being used on every shuttle mission to supply the main shuttle engines. Every person in the United States has passed, or been passed by, a trailer full of these cryogenic liquids. Consequently, it seems to be a common misconception that the technology exists to routinely handle these liquids in space an idea that could not be further from the truth. In fact, while ground handling of these very cold liquids is an everyday practice at NASA facilities, one of the more significant items in causing shuttle delays is the activity dealing with filling the cryogenic tanks.

In the past, the applications of cryogens in space have involved very short time span missions and the high thrust levels of launch. For the few cases where cryogenic liquids have been used after free drift in space, thrusters have been used to accelerate the vehicle and settle the liquids immediately prior to their use. Thus, the only real experience that exists is for applications on the order of hours and at $g$ 
levels which cause the liquid to be settled in the tank. Figure 1 provides a contrast of what has been done to what is required. As can be seen, storage times from months to years are required as is the capability to control the 1 iquid under micro-g conditions and the ability to transfer cryogens from one tank to another without benefit of acceleration forces. The analysis capabilities and design criteria for the future missions simply do not exist. Recognizing this, NASA has, for the past ten years, attempted to establish a program in Cryogenic Fluids Management (CFM) which would address the key technology elements.

As a result of several workshops and meetings with scientists and engineers with experience in the field of cryogenics, all the necessary technology needs (32 different items) have been identified and grouped into 5 major areas. The five technology areas, are; 1) Storage, 2) Transfer, 3) supply, 4) Fluid Handling, and 5) Advanced Instruments. In addition, universal agreement has been reached with respect to both the general technology needs and to the specific needs which will require in space testing to resolve unknowns and reduce design risks for future missions.

Most recently, LeRC and MSFC have conducted a joint effort to review all the planned programs for cryo Fluid Management and to determine what, if any, duplication existed in the activities of the two centers and what technology areas were not being adequately addressed at either center. This effort resulted in the streamlining of the overall program and an agreement between the two centers as to which would be responsible for the various required elements of the program. As a result, the proposed program was taken to NASA $H Q$ and recommended for funding. Key elements consist of the following activities.

1) LeRC will maintain a base $R$ \& $T$ program which will develop the analyses and basic 19 testing fundamental to understanding cryogenic fluid thermal characteristics and dynamic processes. Facilities to support this activity consist of small vacuum chambers and computational equipment.

2) Both LeRC and MSFC will conduct large scale ground tests of liquid nitrogen and liquid hydrogen systems. The MSFC activity will be directed, in general, at demonstrating specific system design characteristics and performance. LeRC, on the other hand, will use the large scale test systems to gather the data necessary to validate computer models and to extend the validated range of CFM design parameters.

3) Both Centers will conduct applicable small scale flight experiments in the shuttle or on sounding rockets to extend the understanding of the governing fluid management equations to low-g applications. The majority of these experiments are expected to use non-cryogenic fluids and most will be funded through the office of Aeronautics and Exploration Technologies (OAET) 
In-Space Technology Experiments Program (IN-STEP) process.

4) LeRC will manage a shuttle experiment using liquid nitrogen to develop pressure control and transfer data under low-g conditions. MSFC personnel will participate in this project and will provide system level testing and test requirements in addition to possibly performing the integration function for the flight hardware. This Shuttle experiment, called The Cryogenic orbital Nitrogen Experiment (CONE) will provide data directly applicable to life support systems. The physical scale and fluid properties are appropriate to most planned manned systems. In addition, it will provide the first og cryogenic data which can be used directly in the design of either $\mathrm{LN}_{2}$ or LOX systems. This data can also be used to generate the first extrapolations for og liquid hydrogen performance.

5) Both centers will work to define the appropriate experiment set to obtain the $\mathrm{LH}_{2}$ data necessary to eliminate the design risk caused by extrapolating from $\mathrm{LN}_{2}$ or $1 \mathrm{~g}$ testing in items 1 through 4 above. This experiment set may consist of some small scale sounding rocket type experiments followed by a shuttle (or large ELV) $\mathrm{LH}_{2}$ experiment. Management responsibility for this area has yet to be established but since it will probably not start until after the CONE flight in 1998, an immediate decision is not mandatory.

While this program has basically been defined by the MSFC/LeRC team, other centers, primarily LaRC, GSFC, and JSC have been helpful in providing consultation and have given full support to the outilined program. The need for this program, including some projected benefits are presented in the following paragraphs as are the specifics of the program at LeRC and MSFC.

\section{REOUIREMENTS \& BENEFITS}

During the last several years, a concerted effort has been made to develop an architecture for the spacecraft which will be required for America's next Lunar and/or Mars missions. Unfortunately, no single architecture has resulted against which specific technology requirements or benefits can be assessed. However, in the case of cryogenic fiuid management, it has been found that the technology requirements are relatively independent of the architecture selected. The overall goals are as shown in Figure 2. As can be seen, many of the goals are an order of magnitude more restrictive that what has been achieved in flight demonstrations to date. Key assumptions that apply to the development of the goals of Figure 2 are a) the vehicles will ultimately require reusability in order to keep life-cycle cost within reason; b) Even for a reusable vehicle, the majority of the Cryo Tankage may be throw-away; c) all missions require significant times in LEO for vehicle build-up; and d) all the mission architectures, including those involving nuclear thermal propulsion, require large quantities of cryogenic fluids. 
Once having established a set of goals for the cryogenic technology, it was then necessary to establish their impact on the overall mission cost. Key parameters in this evaluation are the selection of the design criteria that would be used if the new technology were not developed. This can be thought of as defining the current state-of-the-art. While the selection made has been the matter of some controversy, a general consensus within NASA has been reached and the bottom line in cost savings is shown in Fig. 3 to be in excess of $\$ 20 \mathrm{~B}$ over the life of the Lunar Exploration Program. Changes to the ground rules and assumptions will, or course, affect this number but in any case it would be in the billions of dollars. consequently, it is readily apparent why it is necessary to pursue the development of cryogenic fluid technology and it was that desire which has brought the NASA centers together to define the best possible program which considered not only technology needs but budgetary constraints. The fundamentals of that program are as follows.

\section{The Cryo Ground Program}

To be most effective, the overall ground and flight programs have been coordinated as a single thrust. In other words, the overall technology needs have been evaluated and a total program including $1 \mathrm{~g}$ and og test requirements have been identified. The ground program then consists of the analyses, mathematical modelling, and $1 \mathrm{~g}$ testing that is required so that, when validated through the necessary flight program, future vehicle designs can be based on proven methods and empirical design criteria. The ground program is further coordinated between Marshall Space Flight Center and Lewis Research Center. The split of responsibility is, in general, that LeRC pursues development of general analytical model development and technology while MSFC pursues the demonstration of mission specific design applications.

\section{The LeRC ground program}

The LeRC ground program consists of an integrated analysis and testing approach. The range of potential cryogenic system applications has been evaluated and the analyses that will be required to support flight hardware system designs has been identified. This activity, which vill continue to evolve, has formed the basis for both the analytical modelling plans and proposed testing.

An active analytical model development program is coupled to both small and large scale testing. Tests are planned around the validation and/or empirical generation of the appropriate design criteria. There are three test facilities (and, of course, multiple computational facilities) which support this activity. The smallest, and least complicated test facility is RL-13, Figure 4. This $\mathrm{LN}_{2}$ test facility is convenient for "quick-look" data in support of analyses of heat exchangers, pump/ mixer configurations, and tank fill processes. In addition, RL-13 can be used for initial testing of instrumentation concepts. 
A second facility at LeRC, CCL-7 (Fig. 5), is a somewhat larger facility and is also capable of testing with $\mathrm{LH}_{2}$. It is used to develop data on component and subsystem efficiencies and component tests. Technologies being worked in $\mathrm{CCL} 7$ include insulation material performance, Joule-Thompson valve operational characteristics, flow meter accuracy, and cryo dumping (rapid depressurization and outflow).

K-site (Fig. 6), which is a 25' dia. LH, rated vacuum chamber at the plum Brook Facility in Sandusky is used for both component and system level testing. The $\mathrm{k}$-site chamber can maintain vacuum levels below $10^{-4}$ ton and has a cold wall which can control temperatures between -320 and $+170^{\circ} \mathrm{F}$. Technologies being developed with K-site test data include insulation system performance, pressurization system efficiency, active and passive pressure control system performances, and no-vent fill characteristics. $\mathrm{k}$-site is especially valuable in running system level performance tests since it is able to run tests for weeks at a time and can accommodate several large size tanks simultaneously. This enables the gathering of fluid transfer data on real size hardware.

\section{The MSFC around program}

The MSFC ground program emphasizes subsystem development and focuses on developing specific components and integrated systems for specific applications. There are currently two parts to the MSFC Ground Program. The first is the ongoing baseline test. program which extends through 1992 and consists of test programs in five separate areas. Specifically, these are no-vent fill with freon as a simulant for a cryogen; a foam/multi-layer insulation system test program to demonstrate the effectiveness of earth-to-orbit insulation systems; teflon coated and composite plumbing line performance evaluations and design concept development; integrated chill down and novent fill process evaluations; and performance of trap-type liquid acquisition devices for potential start basket applications. Following the baseline test program, MSFC will embark on testing in the Multipurpose Hydrogen Test Bed (MHTB). The MHTB will demonstrate the operation of a fullscale, state-of-the-art, spacecraft cryogenic fluid storage system (Insulation system). The components, tank, and integration support for this program have been obtained as part of a NASA Research Announcement which was issued in 1990. Initial testing will start in late 1991. Following the MHTB activities, the MSFC ground test program will focus on system demonstrations related to the Lunar and Mars missions.

MSFC's program is based on the application of an existing $20^{\prime}$ dia. and a planned 15' dia. thermal vacuum test facility. Both are liquid hydrogen rated. The 20' facility, as seen in Figure 7 , is equipped with $\mathrm{LN}_{2}$ cold walls and is capable of high vacuum (10-6 Torr) vac. testing. The expected heavy demand for this facility has caused MSFC to plan for re- 
locating and re-activating an existing $15^{\prime}$ dia. test chamber. This activity is planned for completion in 1994 using NASA $C$ of $F$ funding. The first use of this chamber, (which would have capabilities equivalent to the $20^{\prime}$ chamber) is to conduct the system verification and performance baseline tests for the Cryogenic orbital Nitrogen Experiment (CONE), a major flight experiment discussed in detail below. Following the CONE program, the $15^{\prime}$ Chamber will be used for development and system level testing in support of the cryogenic orbital Hydrogen Experiment (COHE), also discussed below. The $20^{\prime}$ chamber will be used to support LTV/LEV and MTV/MEV system demonstrations.

\section{The Flight Program}

The CFM flight program consists of a number of elements and has both non-cryogenic and cryogenic activities.

Non-Cryo elements - The first experiment specifically designed to be a part of the cryo Program was funded via the IN-STEP program and flew in August on the Shuttle Atlantis. This experiment, outlined in Figure 8 and managed be LeRC, was a Tank Pressure Control Experiment (TPCE). It was specifically intended to investigate the low-g fluid mixing and pressure control properties of Freon 113 (a simulant fluid). TPCE was flown as a mixed cargo payload using a Get-Away-special (GAS) container. The Freon was contained in a plexiglass tank and was heated with resistance heaters to create a pressure rise. The fluid was then mixed with an axial jet mixer to confirm pressure decay rate predictions. video, thermal and pressure data were recorded. The final comparisons (predicted versus actual) of mixer performance and pressure rise and decay rates versus time are currently being made and it is expected that a report will be distributed in 1992.

A second experiment, Fluid Acquisition and Resupply Experiment (FARE), managed by MSFC, is shown in Figure 9 . FARE is a flight experiment selected to evaluate and compare the performance of a screen-channel and vane type passive liquid acquisition device (LAD). The approach is to use the same basic hardware that flew previously as a Shuttle mid-deck experiment on STS-51-C in Jan. 1985. This previous experiment was known as the storable Fluid Management Demonstration (SFMD). FARE is fabricated as two modules that mount in place of four lockers in the shuttle Mid-deck area. The supply tank, located in the lower module has a diaphragm type positive expulsion device and the receiver tank, located in the upper module will contain a screen-channel LAD. If there is general success, a second mission using a vane device as a IAD may be flown. Both the supply and receiver tank are transparent acrylic which permits direct viewing (by video cameras) of the liquid behavior during operations. The test fluid is water with a dye added for better viewing. The filling/venting tests and liquid motion observations will be correlated with previous predictions made with FLOW-3D 
(a liquid dynamics analysis program) to assess the ability to predict low-g fluid behavior.

Figure 10 depicts a subscale orbital Fluid Transfer Experiment (SOFTE). This is a flight experiment being managed by MSFC and designed to investigate selected low-g fluid management issues related to liquid acquisition and tank filling with and without venting. The experiment will use a nonhazardous test fluid such as Freon 113, at or near saturation temperature and pressure to simulate the behavior of cryogens. The experiment will be mounted in the shuttle payload bay in two Get-Away-special (GAS) canisters. Again, the tanks will be transparent plastic and the data in the form of videotaped fluid motions and recorded temperatures, pressures and fill levels will be collected to enable 1) characterization of liquid/gas interface behavior as a function of inflow parameters, 2) correlation of fill time and final fill fraction with initial conditions, and 3) estimation of interfacial condensation rates. Preflight analytical predictions will be compared with the experimental data to assess the ability to predict low-g fluid behavior

Vented Tank Resupply Experiment (VTRE), Figure 11, is another IN-STEP experiment and is intended to investigate capillary vanes as a low-g fluid management technique for positioning fluids during venting and outflow. VTRE, managed by LeRC, is in the early design stages but will probably use freon as the fluid and will probably be mounted on a Hitchhiker structure for integration with the shuttle. As with the other experiments, analysis will be developed to predict performance and subsequent to flight, the data will be compared with the analyses and appropriate conclusions and/or modifications to the analytical procedures will be made.

other non-cryo experiments are being planned but have not yet been approved for funding. These include investigation of slosh dynamics, liquid retention screens as a start basket, and a mass gaging capability.

\section{cryo elements -}

The cryogenic flight program consists of two major elements.

CRYOGENIC ORBITAL NITROGEN EXPERIMENT (CONE)

CONE, Figure 12, is a large scale liquid nitrogen experiment being managed by LeRC. MSFC is closely allied to this effort and is responsible for test requirements, system level testing and, possibly, launch package integration. As can be seen in Figure 12, The objectives of CONE are to provide validation of the analytical techniques for predicting active pressure control performance and for predicting the fill levels which can be achieved through the no-vent process. A Phase B program has recently been completed and the phase C/D start is planned for 1993. Currently, cONE is expected to consist of two vacuum jacketed 
tanks. Liquid nitrogen will be pumped back and forth to establish fluid transfer characteristics and both active and passive pressure control systems will be activated (not simultaneously) to provide performance data. A number of other components and processes will also be demonstrated. CONE will provide the first low-g data for a significant size cryogenic system. Because of the size and fluid being used, the cONE data can be used as a direct validation of life support system design analysis models ( $\mathrm{IN}_{2} \&$ LOX). In addition, the data can be used to help with the understanding of $\mathrm{LH}_{2}$ systems although some extrapolation and attendant design risk will be necessary. The flight date for CONE is projected for 1998 .

\section{CRYOGENIC ORBITAL HYDROGEN} EXPERIMENT (COHE)

COHE, Figure 13, is a flight experiment which will be necessary for final validation of $\mathrm{LH}_{2}$ systems design criteria. The LeRC Cryo Fluids Technology office worked for several years to define what came to be known as COLD-SAT, a major liquid hydrogen experiment. However, this experiment was determined to cost upwards of $\$ 300 \mathrm{M}$ and support for such an undertaking was never generated. other experiments were evaluated but no inexpensive, practical, solution was found. A large part of the cost problem is that a $\mathrm{LH}_{2}$ experiment is driven to a large ELV (Delta/Atlas class) because of the risk of flying hazardous cryogens in the shuttle and because of the desire to maximize the applicability of the data by providing acceleration environments and orbit staytimes that are not available within the shuttle.

Consequently, several alternatives are being investigated and include the use of sounding rockets to obtain some limited Hydrogen data, thus minimizing the experimentation, hence cost, of the final experiment design. In any case, the hydrogen experiment would not be initiated until late in the CONE program and would be able to take maximum advantage of lessons learned from the conE activity. In addition, the funding profiles would be coordinated so as not to have overlaps of significant peak requirements.

\section{Ground \& Flight Integration}

As ground and flight data become available, the appropriate analytical models will be validated and a design criteria data base will be established. In all cases, interaction with system designers will be maintained and close scrutiny of their requirements will be maintained. As changes in technology, analytical models, design criteria, or system needs become known, appropriate changes to the Cryogenic Fluid Management program will be made. It is expected that all major technology areas will have been completed by about the year 2005 .

\section{Conclusions}

Through the evolution of what has become the joint LeRC/MSFC CFM Technology Development Program, there has been a consistent, intense effort to coordinate a plan that would meet the needs of NASA, other 
governmental agencies, and industry. The end users of the technology that will be developed through this plan were consulted closely as the plan as formulated, and the needs of end users will continue to drive the program. The current joint LeRC/MSFC CFM Technology Development Program is the best way to deliver the technology necessary to meet the goals and timetables of the space Exploration Initiative.

A flight experiments program is a vital portion of the LeRC/MSFC program, and major flight experiments need to be started now. Delay in beginning a viable flight experiments program would mean delays in obtaining the data necessary to meet SEI goals.
More importantly, NASA currently has the expertise, teamwork, and facilities onhand and is prepared to go forward with this technology development plan. This unique capability in NASA could be at risk if there is a delay in full implementation of the LeRC/MSFC program.

Should the goals and timetables of the SEI change, however, the development of this technology in the near future is stili justified. The analytical tools and design criteria learned through this technology development plan will still be useful whenever they are required; all aspects of this technology development plan will cost much less now than they will in the future. 


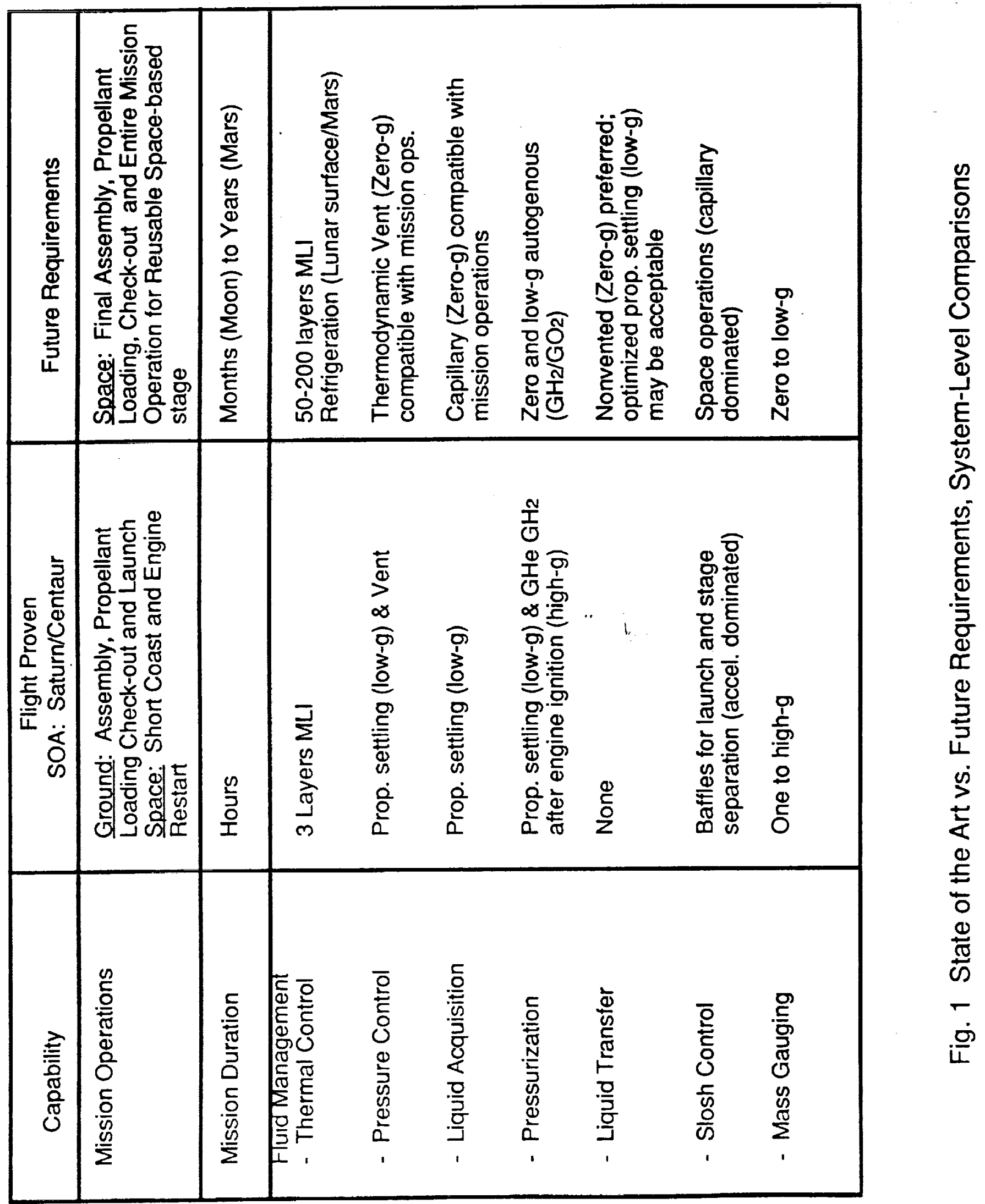




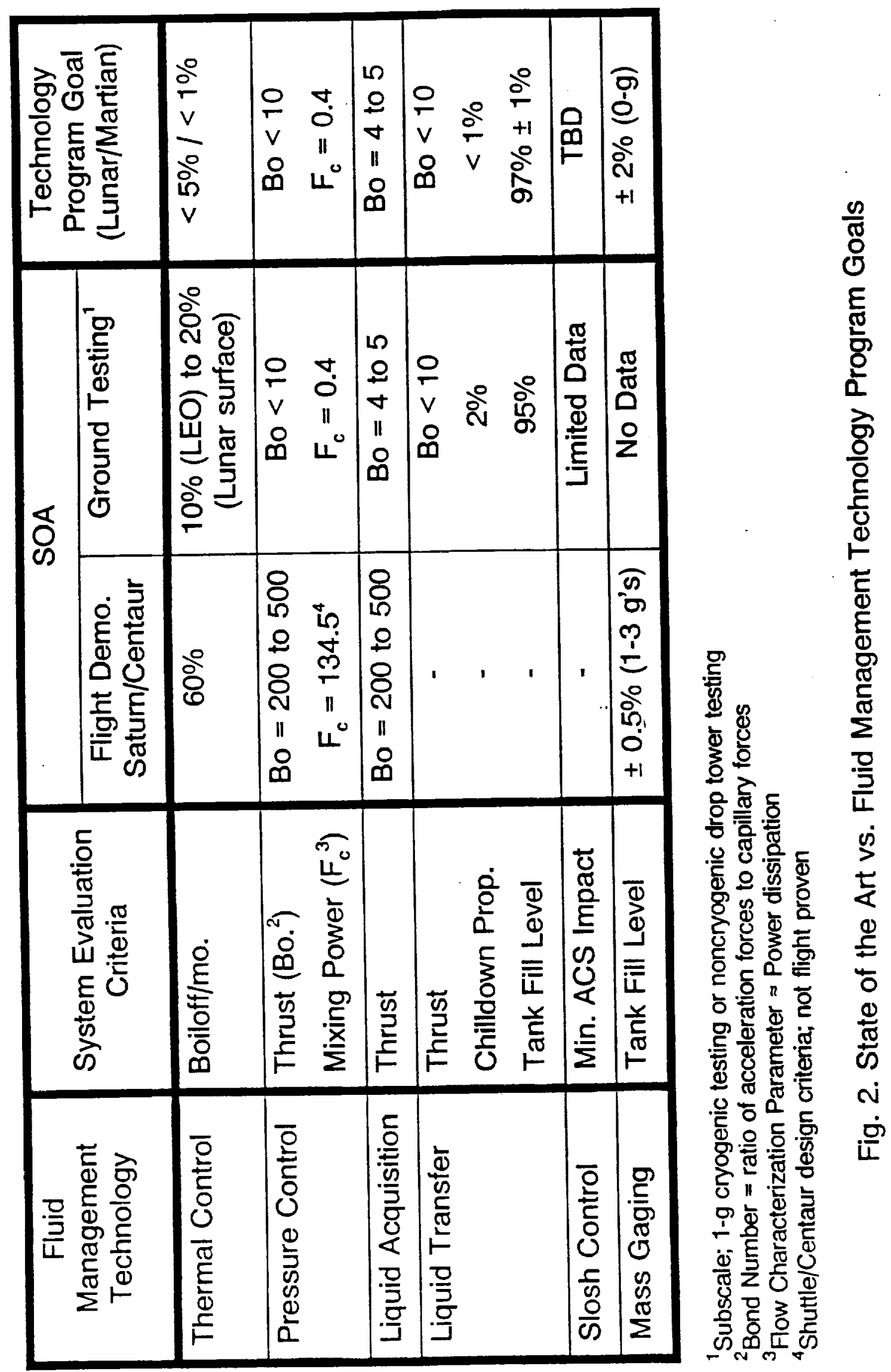

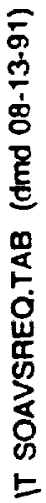


ETO mass savings for nominal mission with 30 day lunar stay

$\begin{array}{lll}\text { - Thermal control } & =28,700 \mathrm{lbm} \\ \text { - Pressure control } & =18,500 \mathrm{lbm} \\ \text { Total mass savings } & =47,200(10 \% \text { LEO mass growth) } \\ \text { Potential cost savings } & =\$ 118 \mathrm{M} / \mathrm{mission} \text { (at } \$ 2500 / \mathrm{bm} \text { ETO cost) }\end{array}$

Benefit of adding a 45 day pre-LEO departure contingency
$\$ .75 \mathrm{~B}$
- Thermal control
- Pressure control
Total mass savings
$=7100 \mathrm{lbm}$
$=4700 \mathrm{lbm}$ Potential cost savings
$=11800 \mathrm{lbm}(2.5 \%$ of LEO mass growth)
$=\$ 29.5 \mathrm{M} / \mathrm{mission}$ (at $\$ 2500 / \mathrm{bm}$ ETO cost)

Additional benefit for 6 month lunar stay

- Thermal control $\quad=58,000 \mathrm{lbm}$

$\begin{array}{ll}\text { - } & \text { Pressure control } \\ \$ 7.8 \mathrm{~B} & =52,000 \mathrm{lbm} \\ \text { - Advanced thermal control } & =14,700 \mathrm{lbm}\end{array}$

Total mass savings

Potential cost savings

$=124,700 \mathrm{lbm}$ (26\%LEO Mass growth)

$=\$ 312 \mathrm{M} / \mathrm{mission}$ (at $\$ 2500 / \mathrm{lbm}$ ETO cost)

Additional Benefit of a tanker/depot (top-off, core \& aerobrake tank fueling)

- For nominal mission with 30 day lunar stay $=5,600 \mathrm{lbm}$

$\$ 1.6 \mathrm{~B}$ - For 45 day pre-LEO departure contingency $=18,500 \mathrm{lbm}$

- For 180 day lunar stay $=1,800 \mathrm{lbm}$

Total mass savings $=25,900 \mathrm{lbm}(5.4 \%$ of LEO mass growth)

Potential cost savings $=\$ 64.75 \mathrm{M} / \mathrm{mission}$ (at $\$ 2500 / \mathrm{lbm}$ ETO cost)

Major benefit of transfer technology is enabling of reusable LTS concepts (Life Cycle Cost Savings of approximately $\$ 10 \mathrm{~B}$ estimated by Martin Marietta)

Total Benefit for 25 Lunar Missions $=\$ 23 \mathrm{~B}$

Fig.3 Benefits of Orbital Cryogenic Propellant Resupply for LTV 


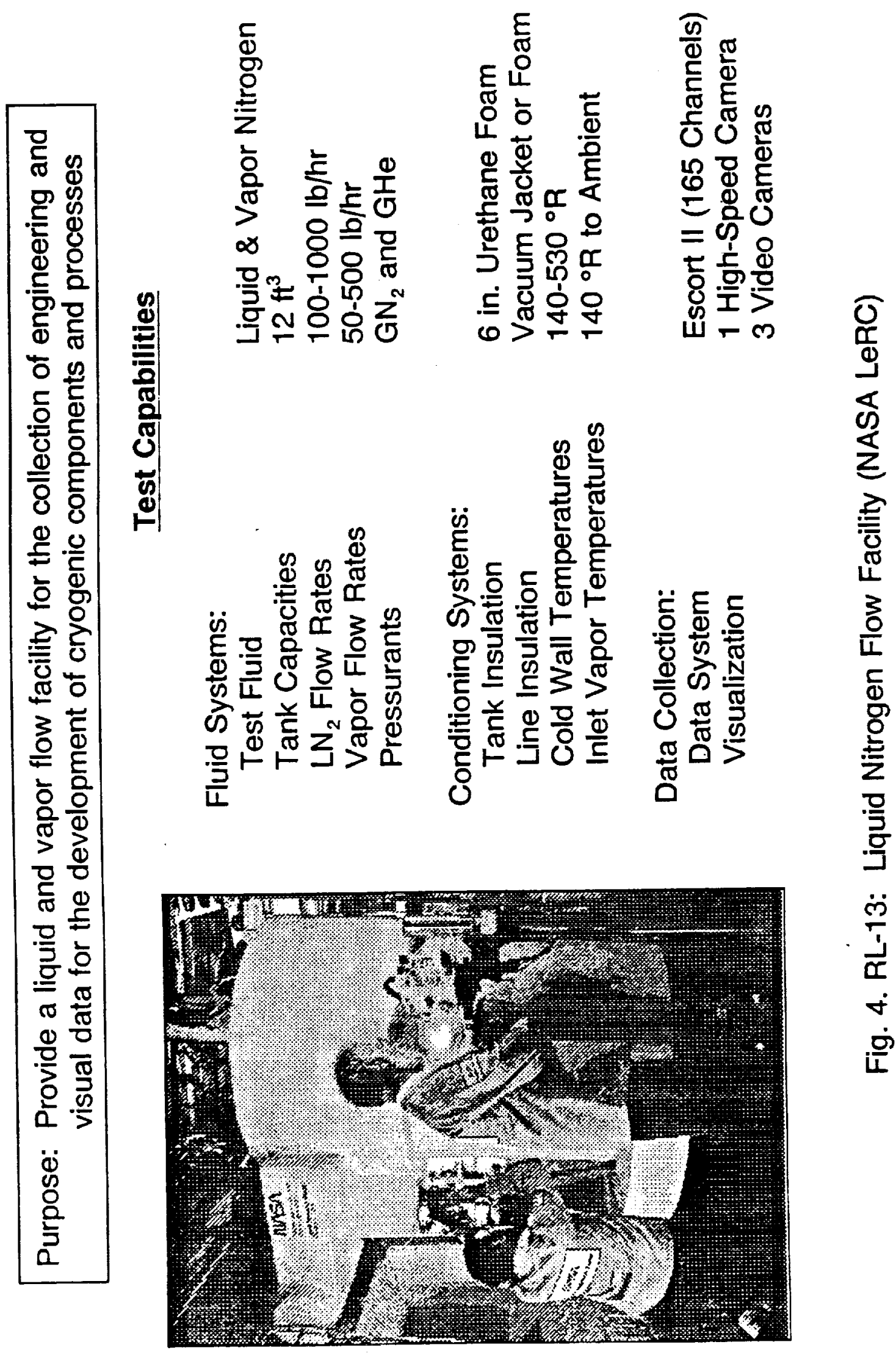



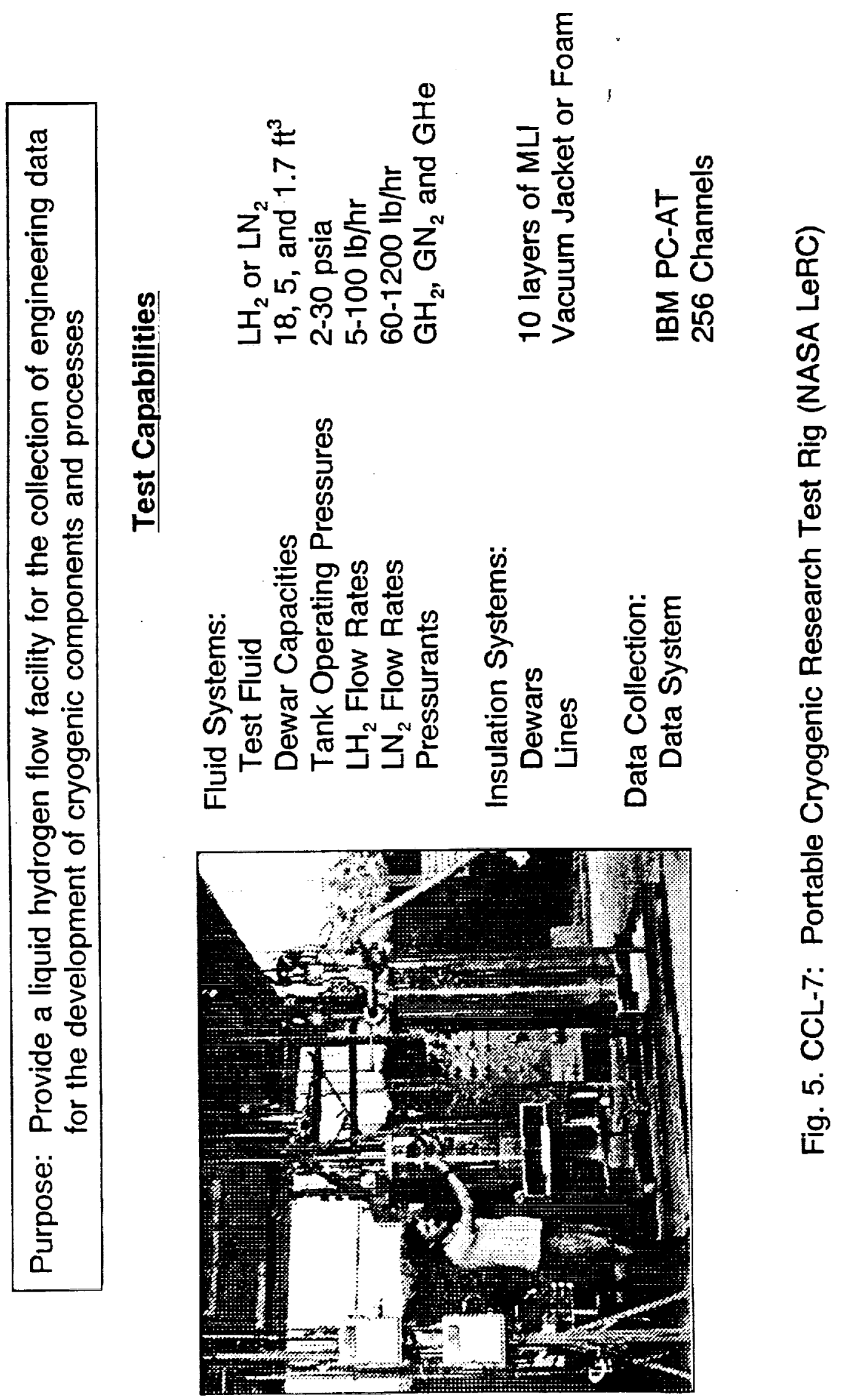

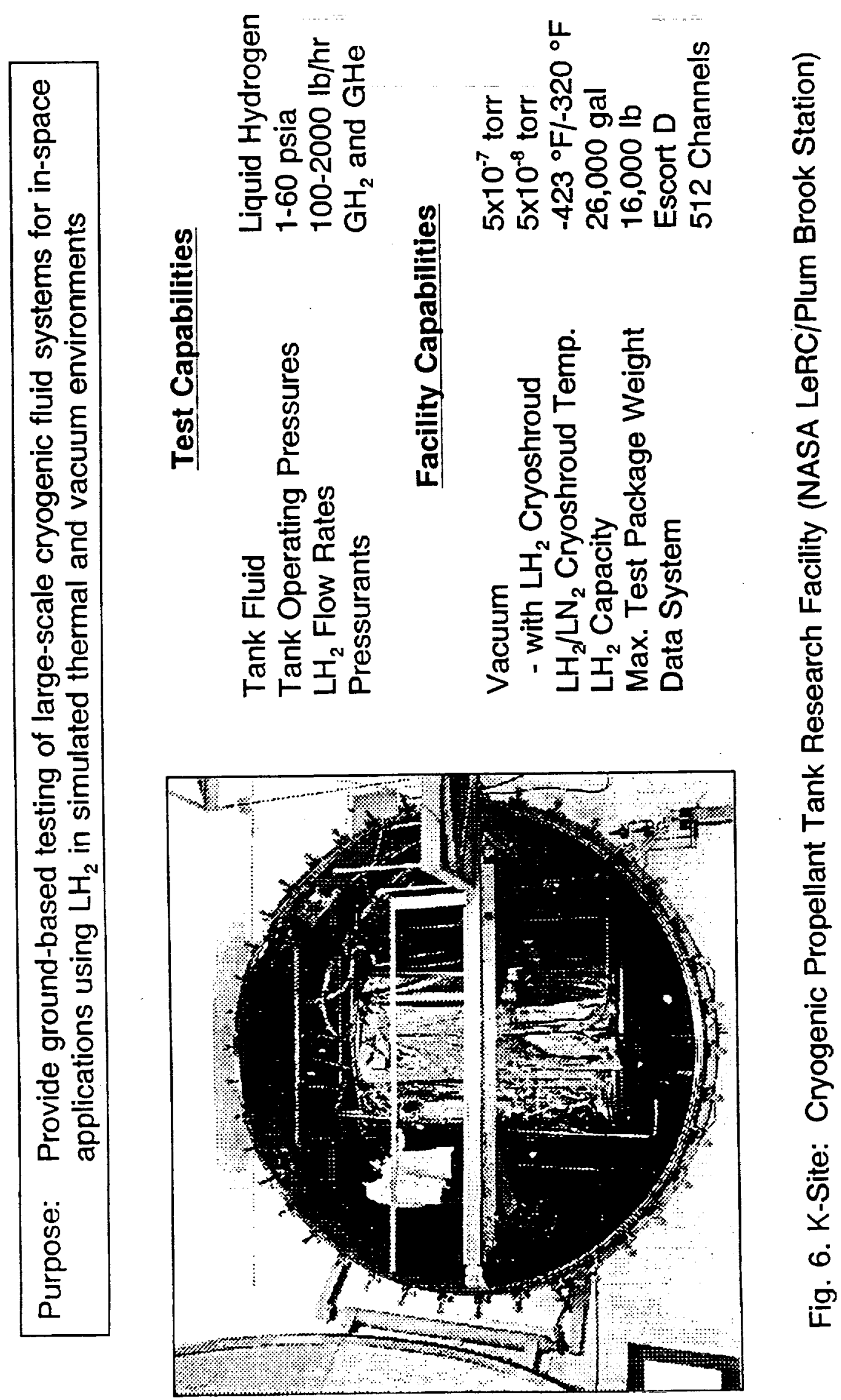

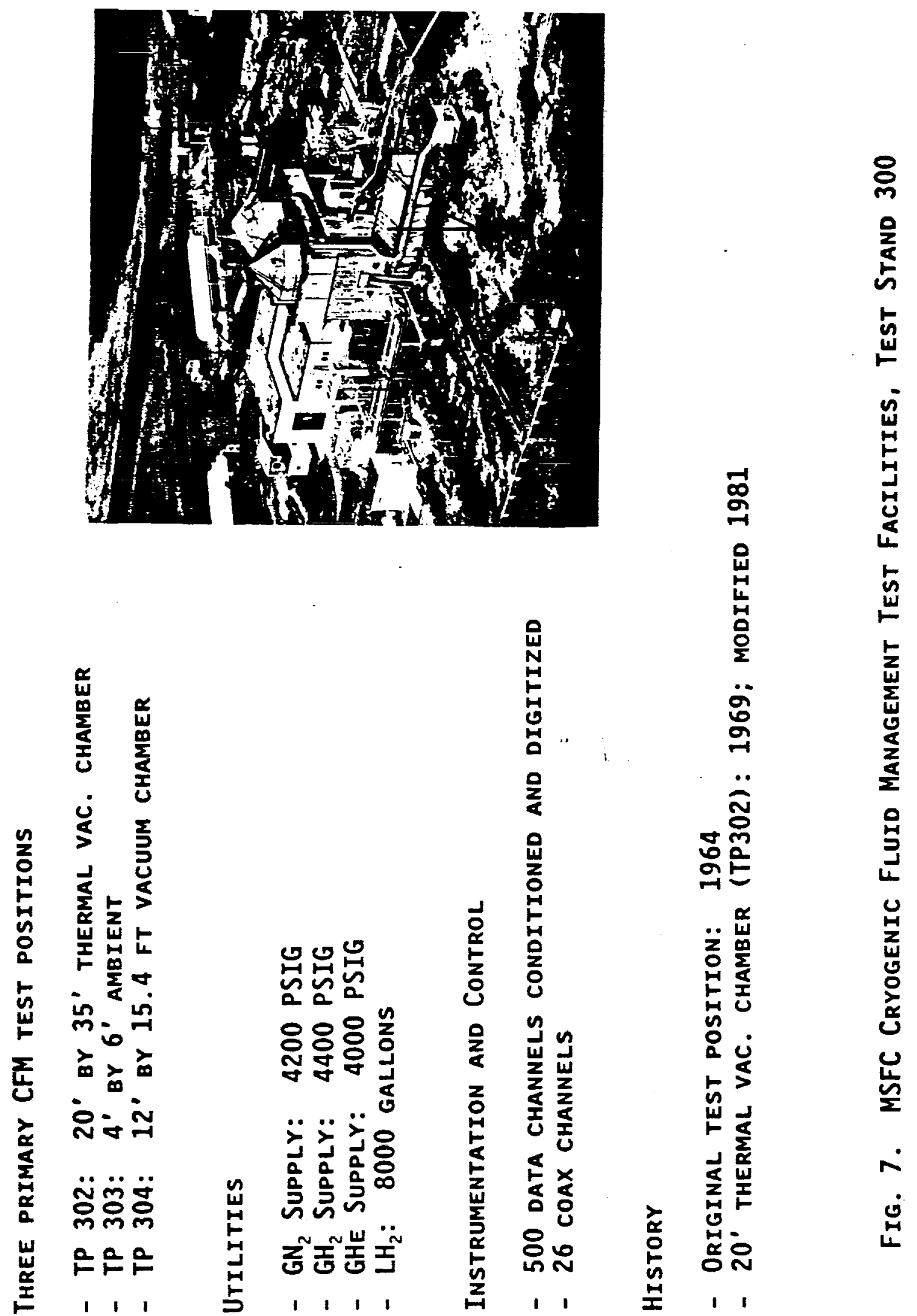


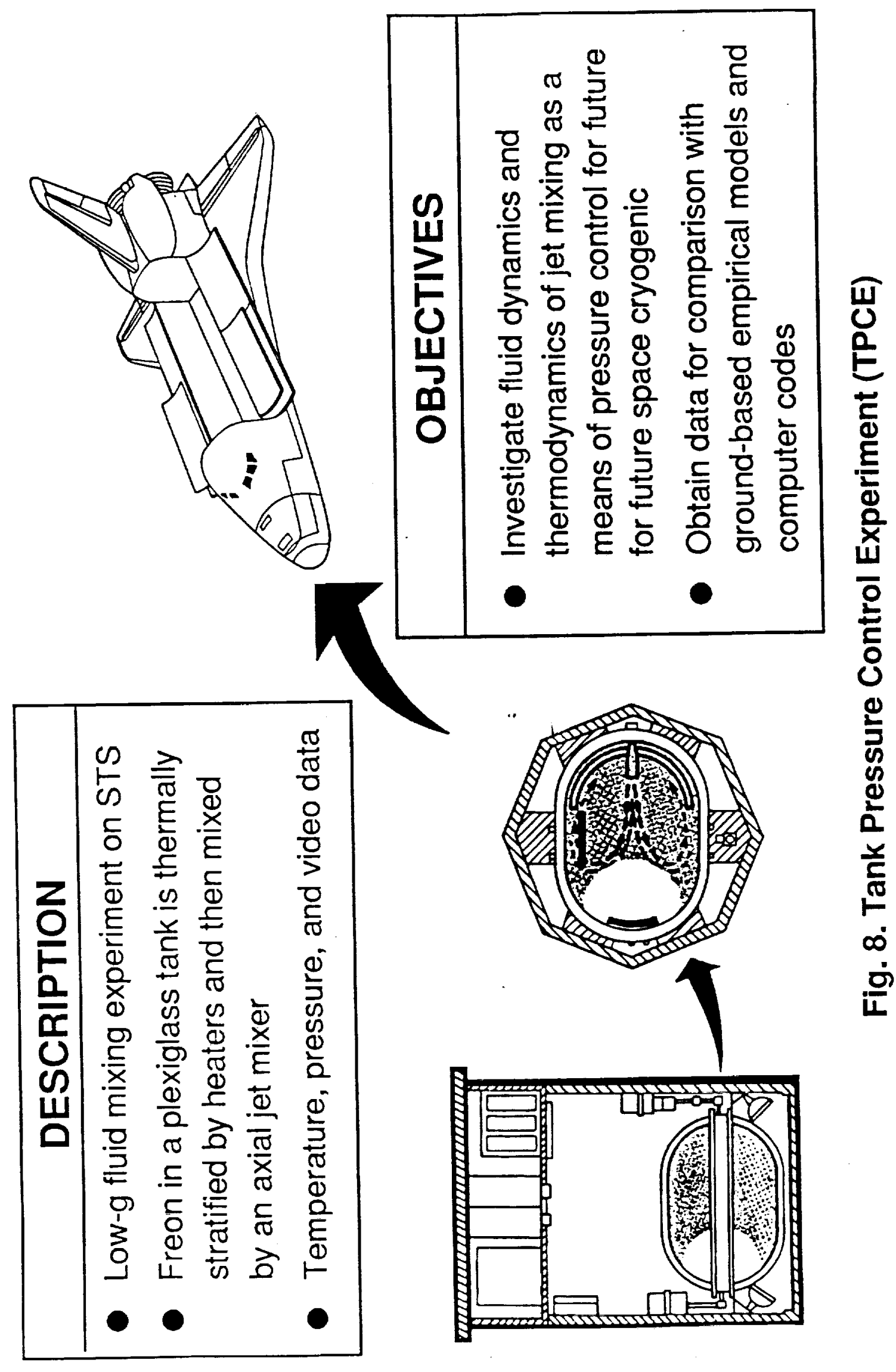



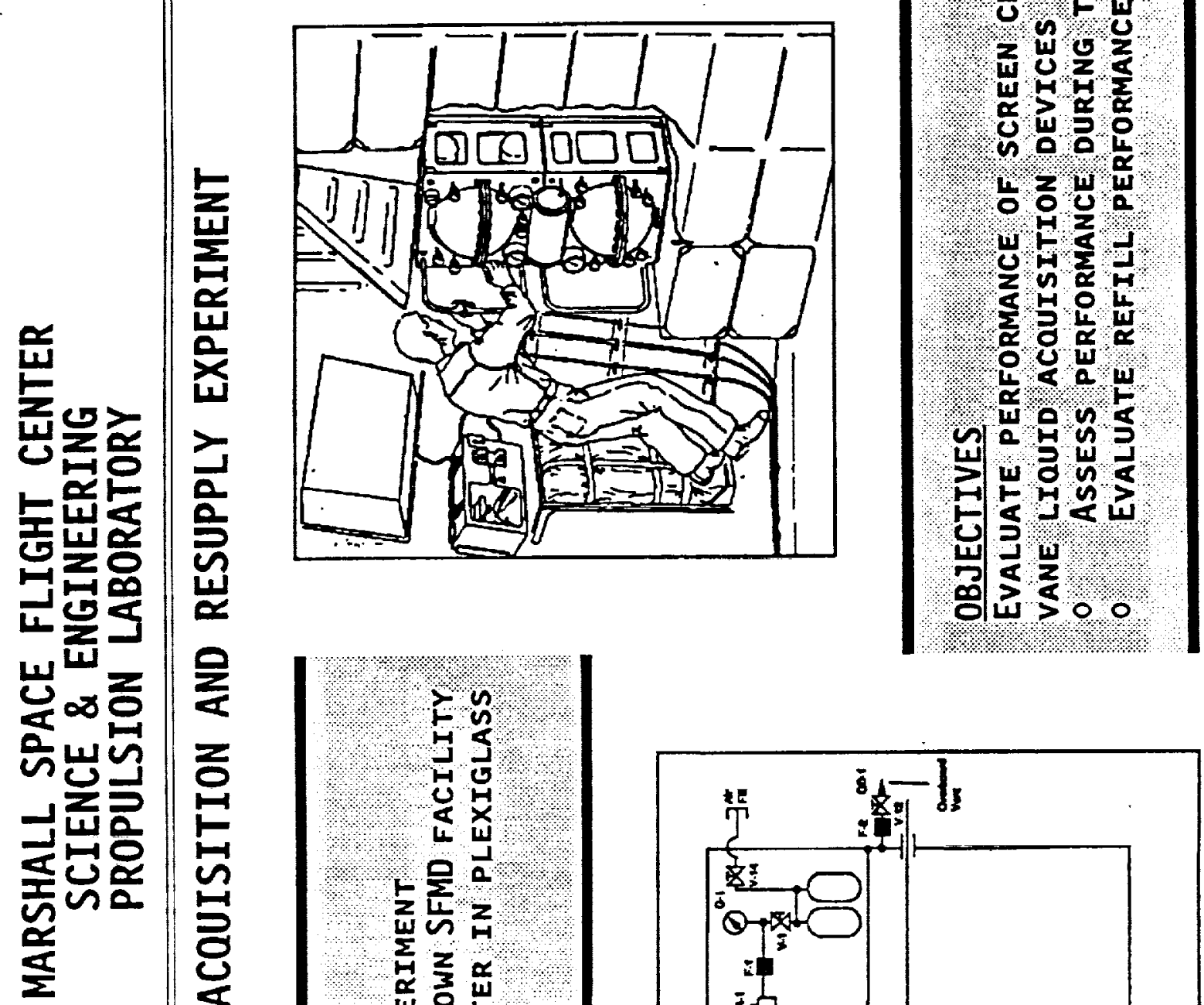

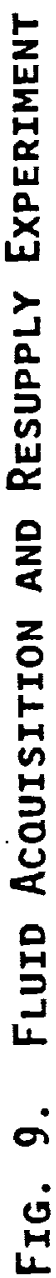




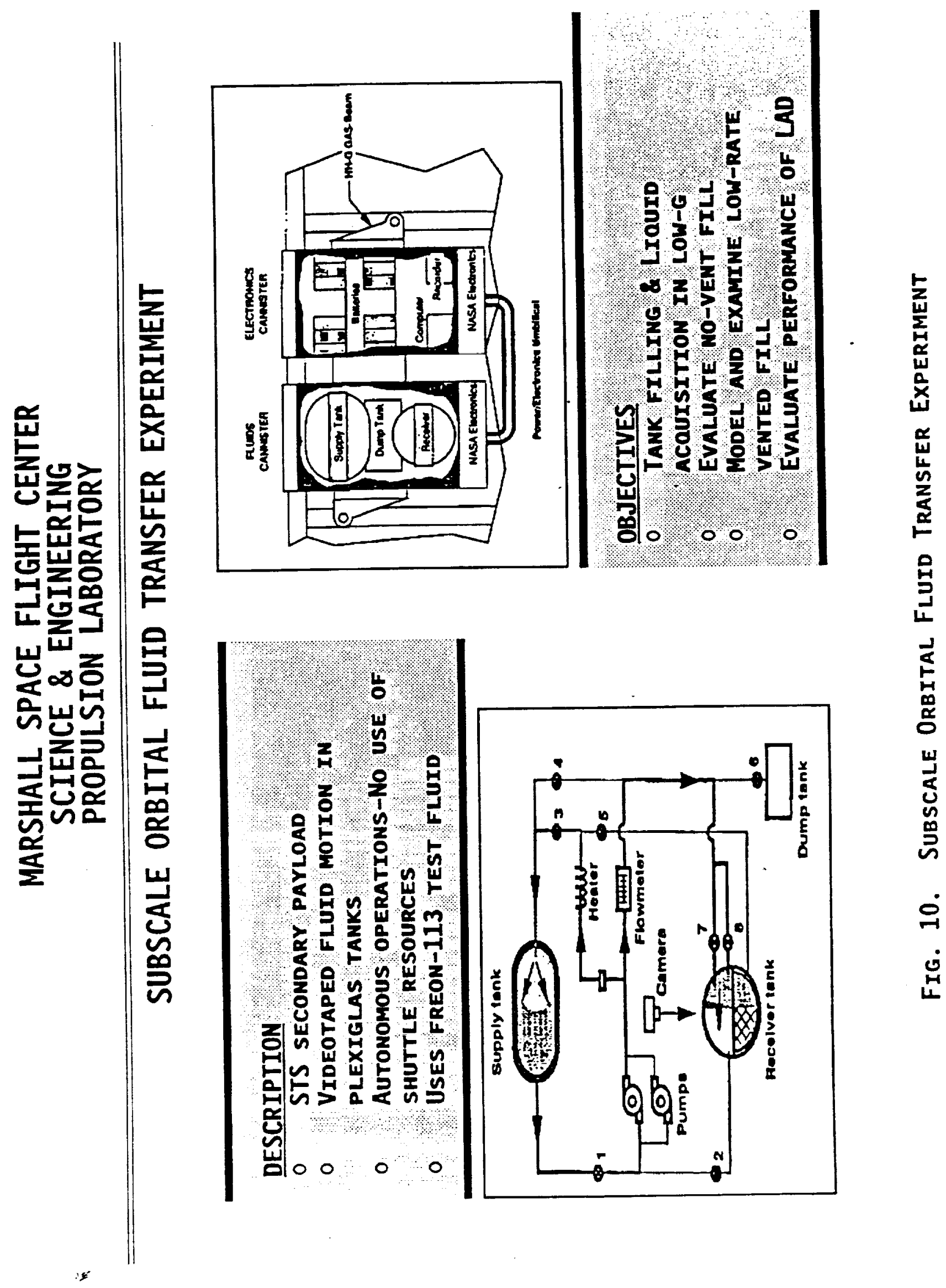



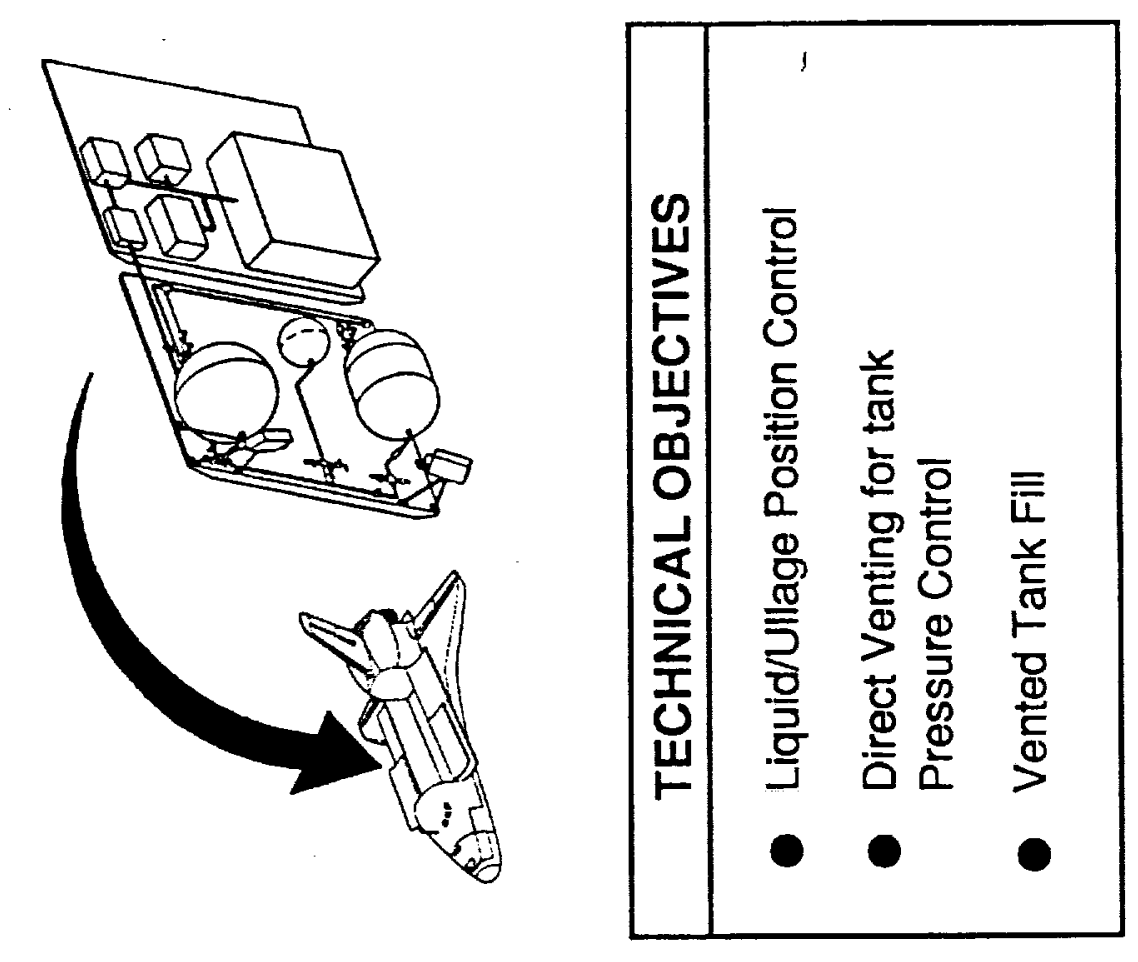

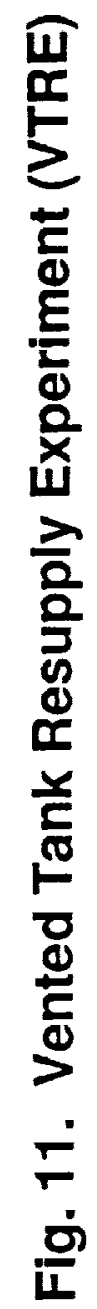
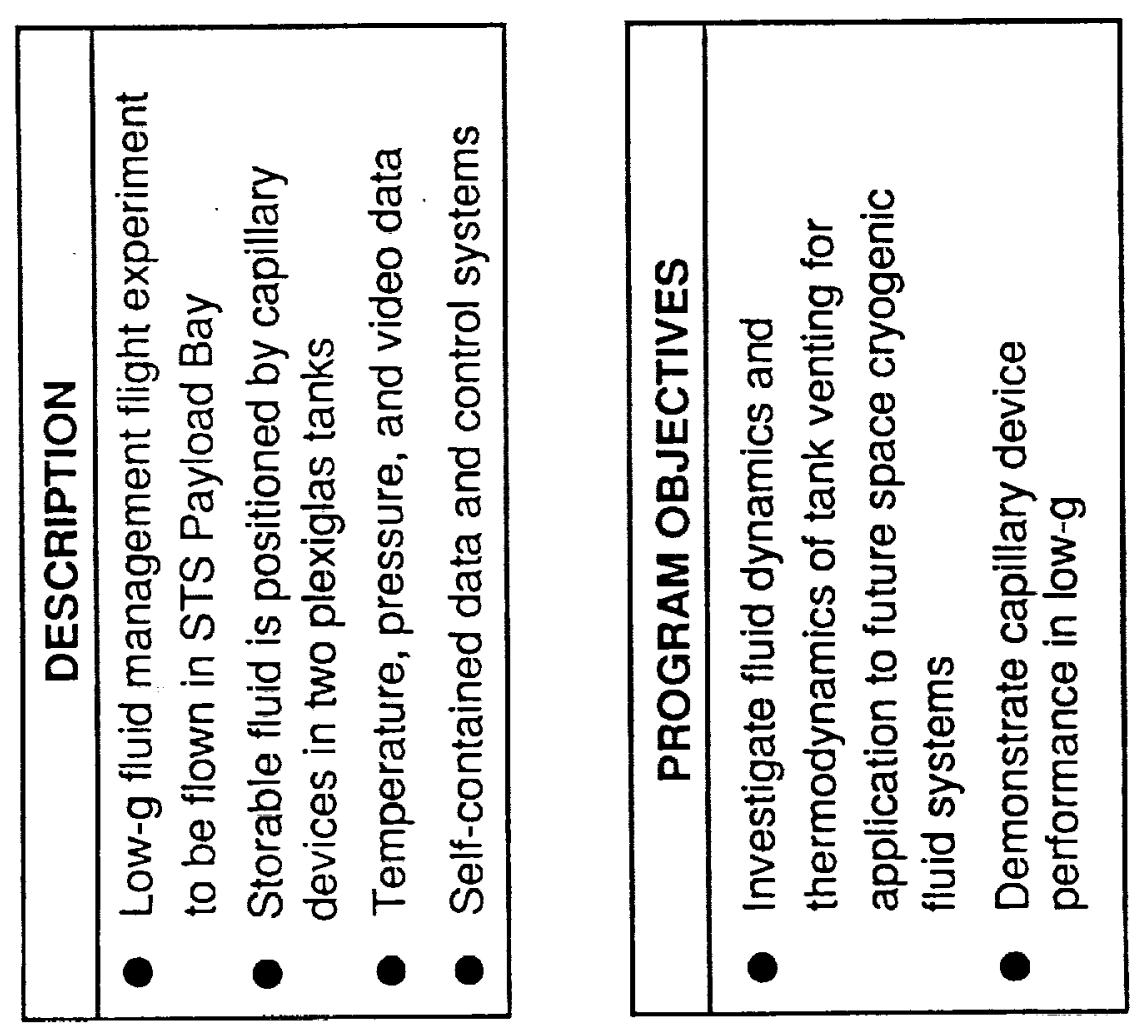


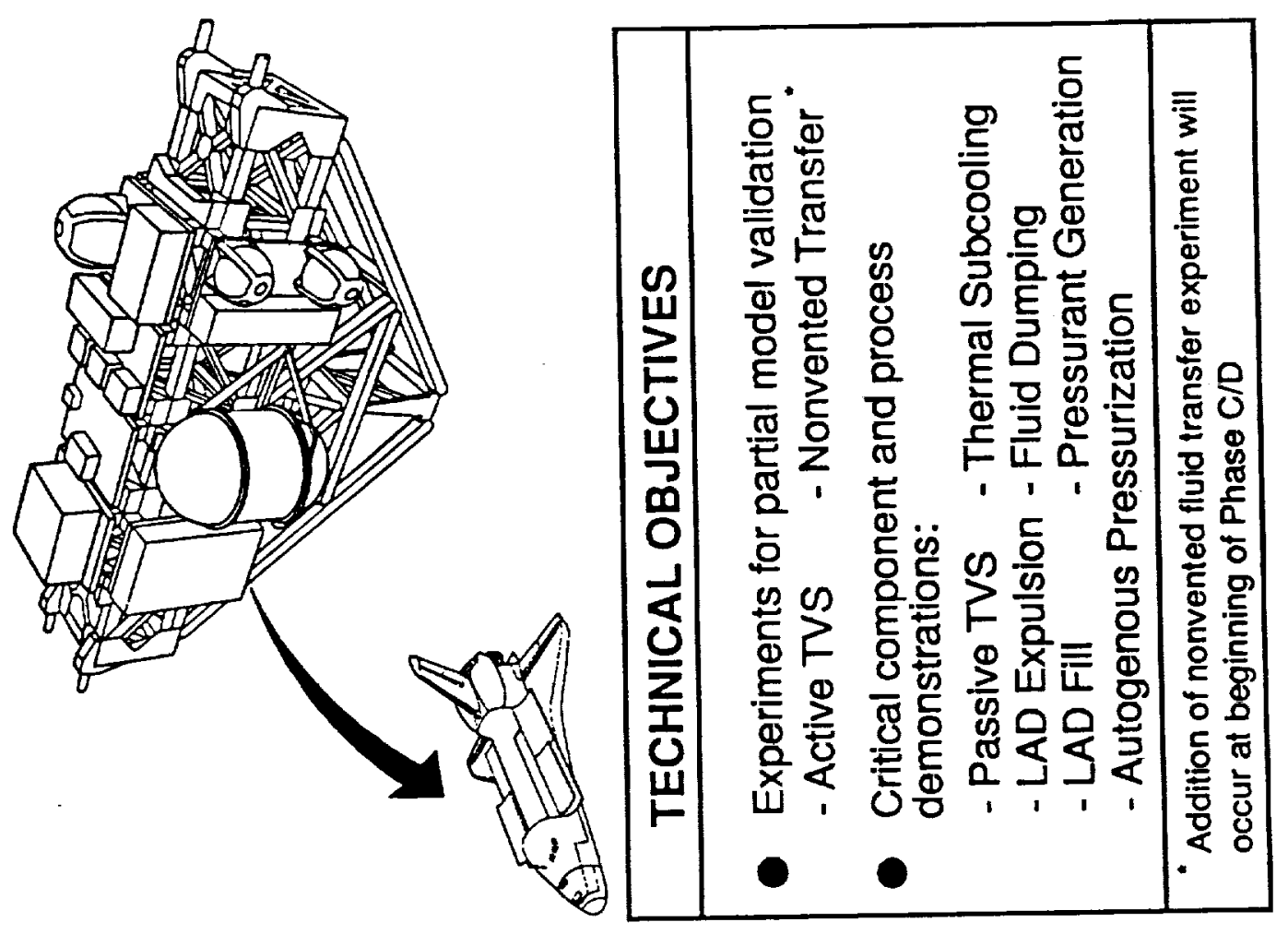

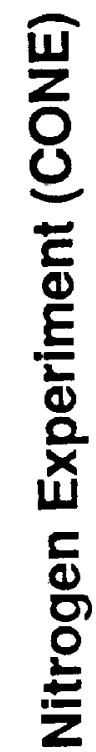
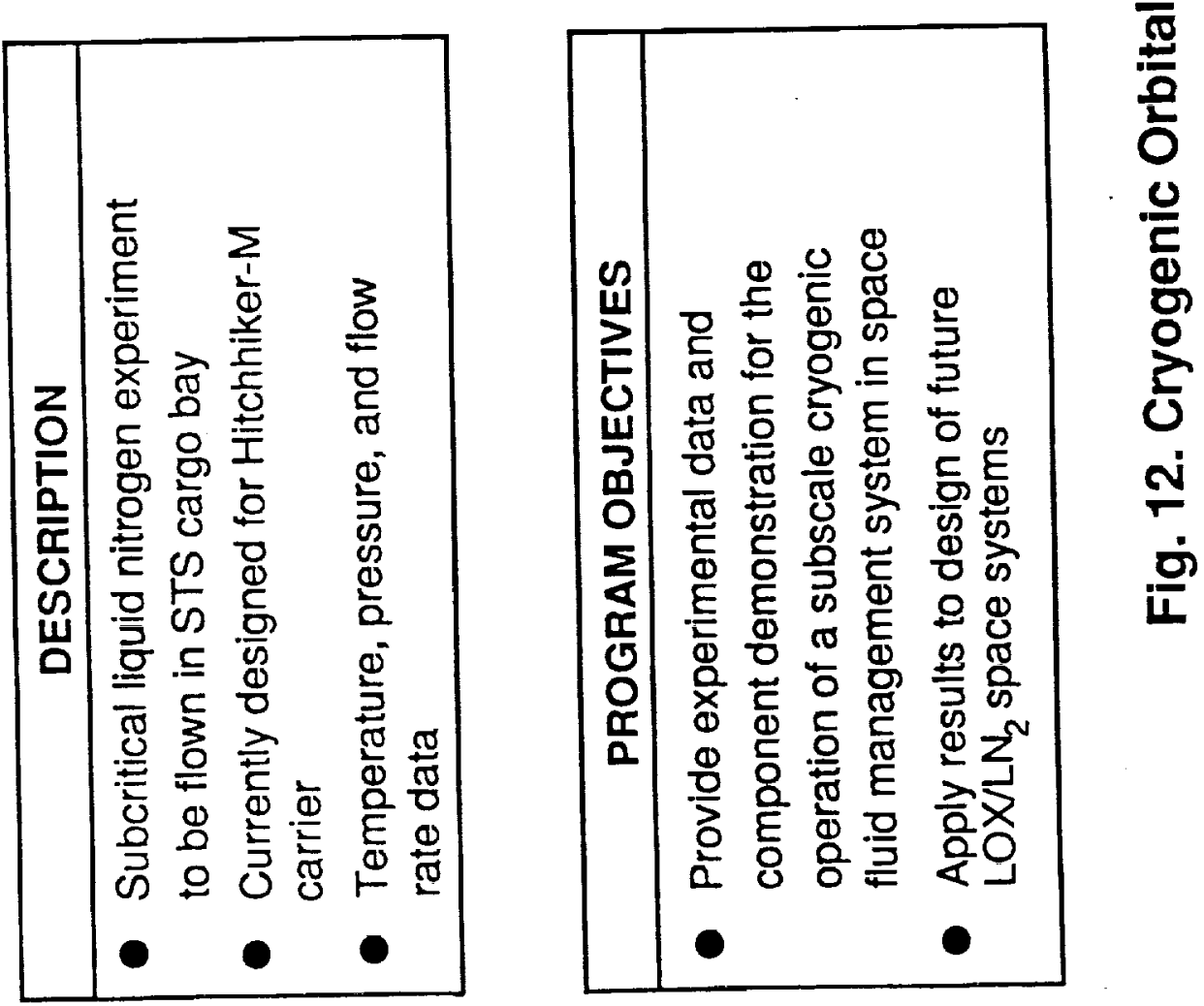

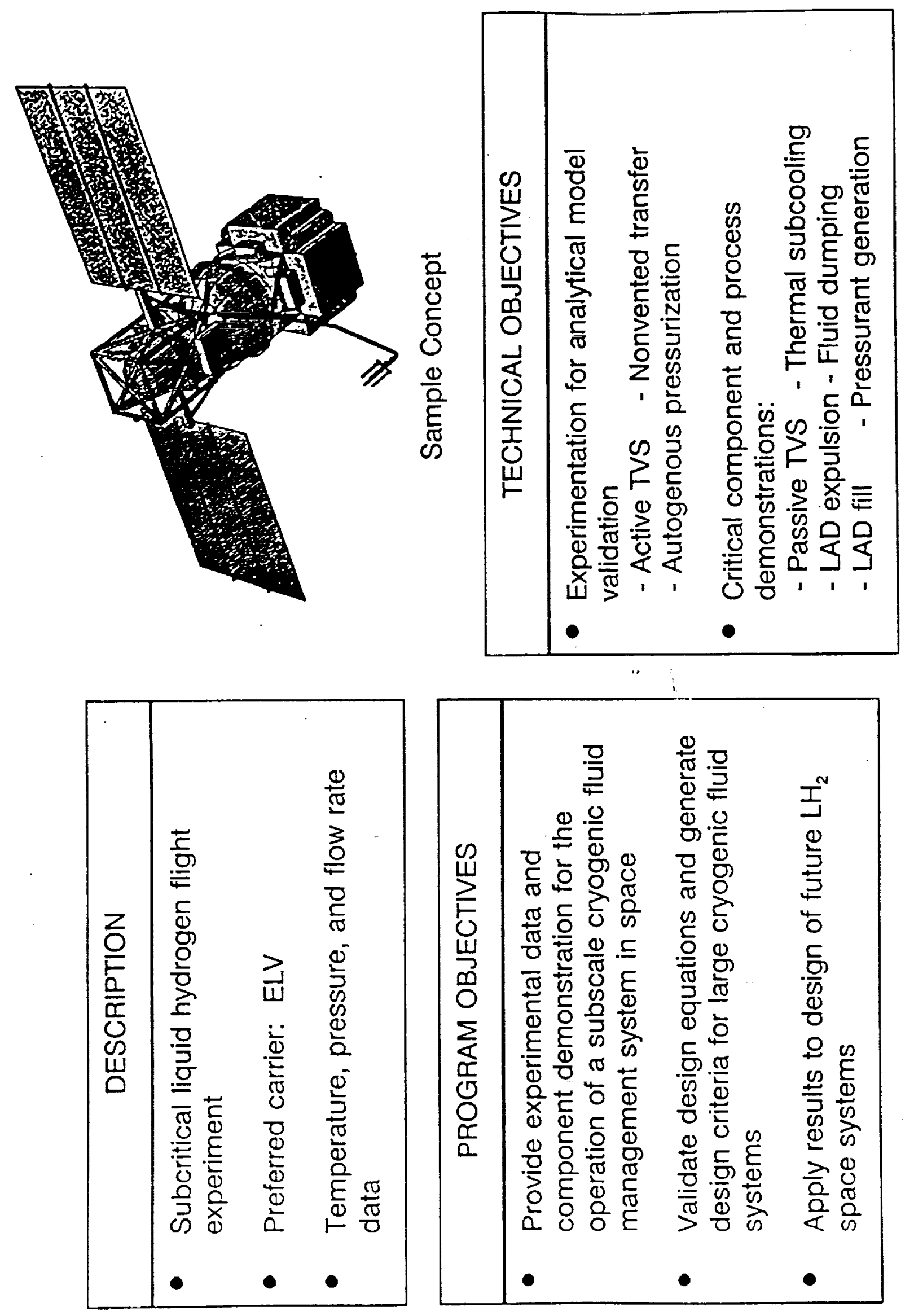

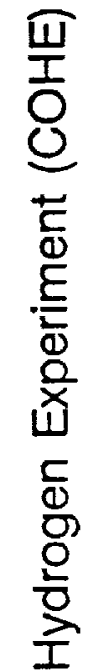

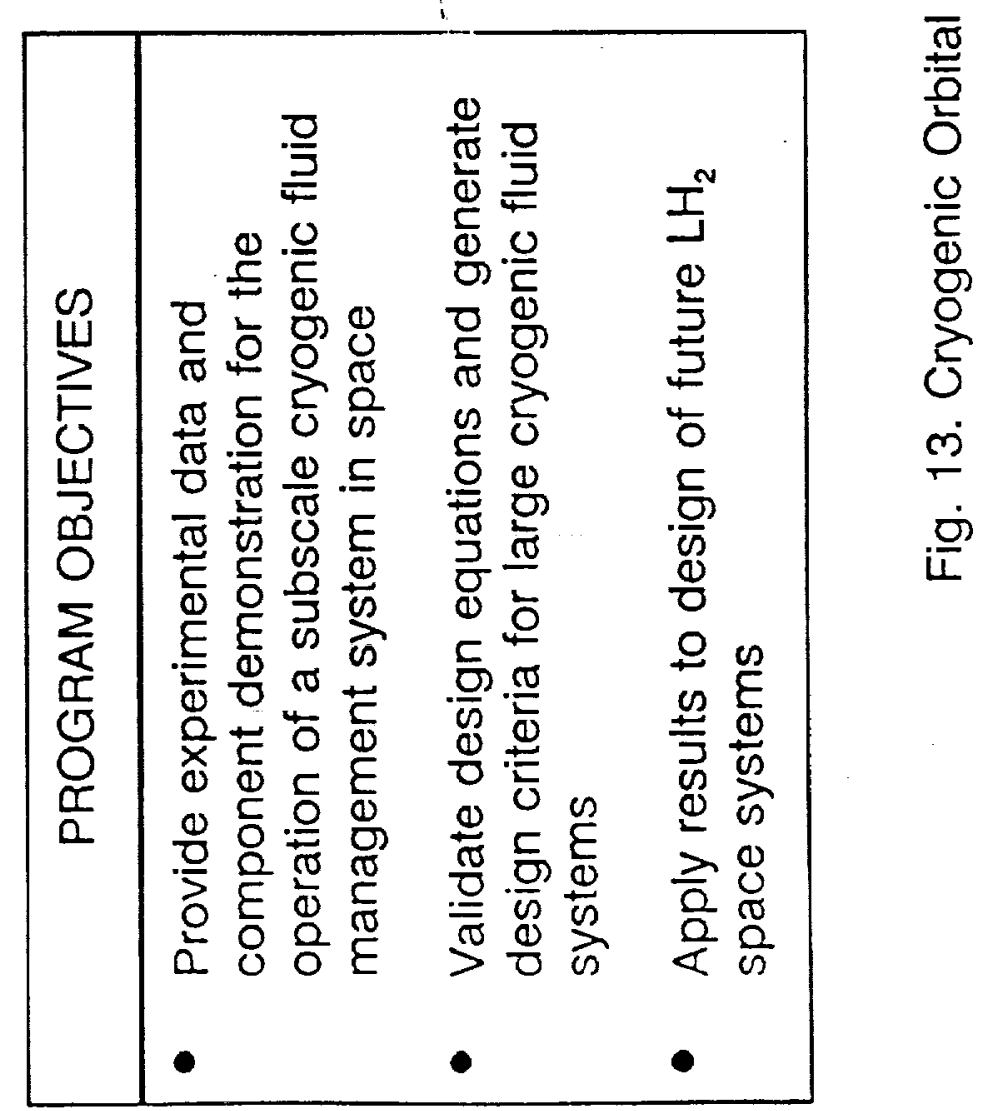




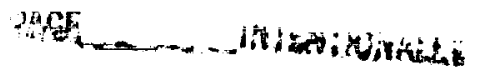

sand

,

$i$ 


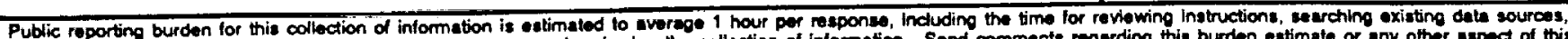
Puttering and mainteining the date needed, and completing and rovlowing the collection of information. Send comments regerding this burden estimate or eny other aspact of this

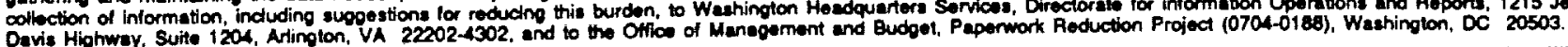

\begin{tabular}{|l|l|r|}
\hline 1. AGENCY USE ONLY (Leave blank) & $\begin{array}{r}\text { 2. AEPOAT DATE } \\
\text { September } 1991\end{array}$ & $\begin{array}{r}\text { 3. REPORT TYPE AND DATES COVERED } \\
\text { Technical Memorandum }\end{array}$
\end{tabular}

\section{TITLE AND SUBTITE}

The NASA Cryogenic Fluid Management Technology Program Plan

6. AUTHOR(\$)

James R. Faddoul and Stanley D. McIntyre

7. PERFOAMINO ORQANIZATHON NAME(S) AND ADDAESS(ES)

National Aeronautics and Space Administration

Lewis Research Center

Cleveland, Ohio 44135-3191

9. SPONSORING/MONITORING AOENCY NAMES(S) AND ADDRESS(ES)

National Aeronautics and Space Administration

Washington, D.C. 20546-0001
WU-506-42-73

6. PERFORMING OAGANIZATION REPORT NUMBER

E-6586

10. SPONSORINO/MONITORING AOENCY REPORT NUMBER

NASA TM-105256

ALAA-91-3553

11. SUPPLEMENTARY NOTES

Prepared for the Conference on Advanced Space Exploration Initiative Technologies cosponsored by AIAA, NASA, and OAI, Cleveland, Ohio, September 4-6, 1991. James R. Faddoul, NASA Lewis Research Center; Stanley D. McIntyre, NASA Marshall Space Flight Center, Huntsville, Alabama. Responsible person, James R. Faddoul, (216) 433-6322.

12.. DISTAIBUTION/AVALLABILITY STATEMENT

12b. DISTRIBUTION CODE

Unclassified - Unlimited

Subject Categories 34 and 20

\section{ABSTAACT (Maximum 200 words)}

During the past three decades, NASA has been designing and using large quantities of cryogenic fluids for propulsion system propellants, coolants for experiments, and for environmental control systems. As a consequence, an erroneous conclusion has been drawn that the technology exists for using large quantities of cryogens in space for long periods of time. This paper attempts to dispel that myth and to present the technology needs that require development in order to support the NASA programs of the future. A NASA program, developed through the impetus of MSFC and LeRC personnel and supported by all NASA centers is outlined. The current State-of-the-art is discussed along with specific needs for near future missions. Then, using the Space Exploration Initiative mission set, cost/benefit projections are made for development of advanced cryogenic fluid management techniques. Earth based and space based test programs are discussed relative to the technology requirements for liquid storage, supply, and transfer and for fluid transfer and advanced instrumentation.

\section{SUBJECT TEAMS}

Cryogenics; Liquid hydrogen; Cryogenic technology; Liquid nitrogen; Liquid oxygen

15. NUMBER OF PAGES 24

16. PRICE CODE

\begin{tabular}{l|c|c|}
\hline $\begin{array}{c}\text { 17. SECUATY CLASSIFICATION } \\
\text { OF REPORT } \\
\text { Unclassified }\end{array}$ & $\begin{array}{c}\text { 18. SECURITY CLASSIFICATION } \\
\text { OF THIS PAGE } \\
\text { Unclassified }\end{array}$ & $\begin{array}{c}\text { 19. SECURITY CLASSIFICATION } \\
\text { OF ABSTACT } \\
\text { Unclassified }\end{array}$ \\
\hline
\end{tabular}

